\title{
用表面增强拉曼散射研究 $\mathrm{C}_{60}$ 、 $\mathrm{C}_{70}$ 分子在银表面的吸附*
}

\author{
李特新 莫育俊 刘竟青 赵铁男 刘玉龙 \\ (中国科学院物理研究所, 北京 100080) \\ 李玉良姚纤新扬德亮 正小红朱道本 \\ (中国科学院化学研究所, 北京 100080)
}

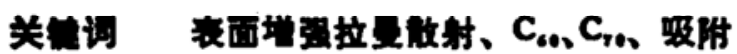

Kroto 等提出的 $\mathrm{C}_{60} 、 \mathrm{C}_{70}$ 分子结构 ${ }^{[1]}$, 已被红外和拉曼光谱证实 ${ }^{[2,3]}$. 现在已经知道, $\mathrm{C}_{60}$ 分子是由长键和短键构成的 20 个六边形环和 12 个五边形环连接起来的截角 20 面体, 具有 Ih 对称性; $C_{70}$ 分子则由 25 个六边形环和 12 个五边形环连接而成的椭球状分子, 对称点群 为 $D_{s \mathrm{~h}}$. 它们的拉曼活性振动模式按对称性分类分别为 $2 \mathrm{Ag}+8 \mathrm{Hg}, 12 \mathrm{~A}_{1}+22 \mathrm{E}_{2}^{\prime}+19 \mathrm{E}_{1}^{\prime \prime(4-6)}$.

表面增强拉曼散射 (Surface-enhanced Raman scattering, SERS), 由于具有高的探测 灵敏度、高分辨率和实时检测等特点, 已经成为测量表面吸附分子振动光谱、研究分子与表面 相互作用的有力手段。在本文中, 我们利用 SERS 研究了 $\mathrm{C}_{60} 、 \mathrm{C}_{70}$ 分子在银表面的吸附性质, 发现 $C_{60} 、 C_{70}$ 分子在银表面属物理吸附性质, 而且, 至少对 $\mathrm{C}_{70}$ 分子, 吸附具有单层饱和效应。

\section{一、实验}

在作 SERS 研究时, 把纯度为 $99 \%$ 的 $\mathrm{C}_{60}, 85 \%$ 的 $\mathrm{C}_{70}$ 配制成 $8 \times 10^{-3} \mathrm{~mol} / \mathrm{L}$ 的分析纯 甲苯溶液, 取 $5 \mu \mathrm{L}$ 溶液滴在化学腚积的银镜 ${ }^{m}$ 上, 待甲苯完全挥发后, 在 SPEX-1403 谱仪上 进行拉曼测量. 激发光源为 $\mathrm{Ar}^{+}$激光器 $(488 \mathrm{~nm})$, 采用柱面镜和 $45^{\circ}$ 背散射, 狭漣宽 400 $\mu \mathrm{m}$, 琏高 $2 \mathrm{~cm}$. 正常拉曼谱由压片的 $\mathrm{C}_{60} 、 \mathrm{C}_{70}$ 粉末获得, 此时采用 $180^{\circ}$ 背散射, 两种实验条 件下,到达样品表面的功率均不超过 $5 \mathrm{~mW}$.

\section{二、结果与讨论}

$\mathrm{C}_{60}$ 分子的正常拉曼谱(以下称拉曼谱)和 SERS 谱分别见图 1、图 2.

拉曼谱中几个较强的䀱为 $272,432,492,710,770,1426,1468$ 和 $1572 \mathrm{~cm}^{-1}$, 在 SERS 谱 中, 几个较强的峰为 $268,432,492,710,770,1426,1468$ 和 $1572 \mathrm{~cm}^{-1}$. 从总体来看, 增强效果 是明显的, 因为用较小的激光功率可得到信噪比更好的谱图, 两个被公认为 $\mathrm{Ag}$ 全对称振动 模的峰 492 和 $1468 \mathrm{~cm}^{-1}$ 在 SERS 㙕中相对于其它峰增强更为明显, 因此相对强度变大. 另 外, 除了第一个峰的位置相差 $4 \mathrm{~cm}^{-1}$ 以外, $\mathrm{C}_{60}$ 分子的拉曼谱和 SERS 谱中别的峰的位置没

1992-02-09 收稿, 1992-04-15 收售改稙

- 国家自然科学基金和国家盍导中心资助项目 


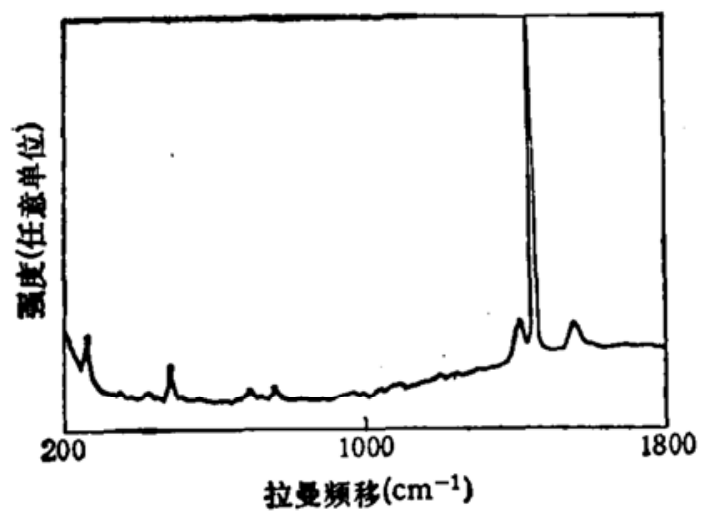

图 $1 C_{00}$ 分子的拉曼谱

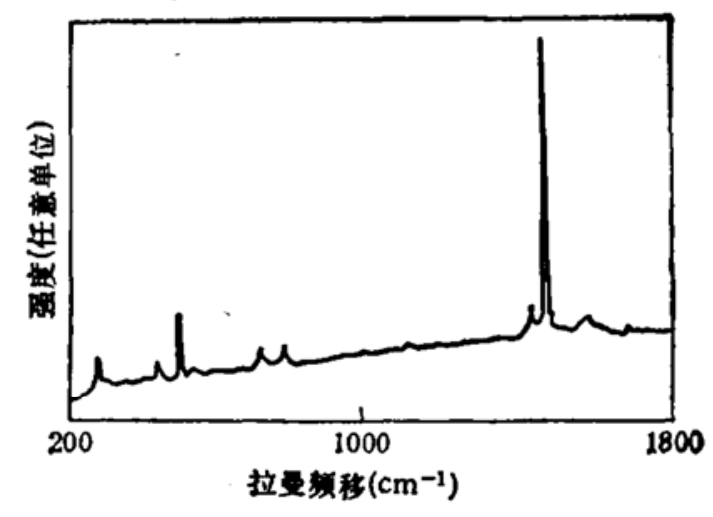

图 $2 C_{0 .}$ 分子的 SERS 谱

有明显移动, 而且在低波数没有观察到 $\mathrm{C}_{60}$ 分子与银表面相互作用所产生的新的振动蜂. 对 $\mathrm{C}_{70}$ 分子由于振动模式较多, 细致的研究工作进行较为困难, 文献 [8]报道了初步的结果. 从 我们已做出的 $\mathrm{C}_{70}$ 分子的正常拉曼谱和 SERS 谱上, 注意到 SERS 谱比拉曼谱多了大约 20 个峰, 达 40 个之多, 主要原因是 SERS 的高灵敏度. 通过对 $\mathrm{C}_{70}$ 分子拉曼谱和 SERS 谱的 比较,发现在拉曼谱和 SERS 谱中都出现的峰的相对强度变化不明显, 这表明 $\mathrm{C}_{70}$ 分子与银表 面之间的相互作用很弱. 上述结果表明: 在我们所采用的实验过程中, $\mathrm{C}_{60} 、 \mathrm{C}_{70}$ 分子在银表面 属于物理吸附性质.

考虑到 $\mathrm{C}_{60} 、 \mathrm{C}_{70}$ 分子具有高的对称性, 它们吸附在银表面时, 属于非极性分子吸附于金属 表面, 分子与表面相互作用主要来自诱导偶极子产生的范德瓦尔斯 (Van der Waals) 力, 这 种弱的相互作用不足以使 $\mathrm{C}_{60}$ 和 $\mathrm{C}_{70}$ 分子发生显著变形, 即 $\mathrm{C}_{60}$ 和 $\mathrm{C}_{70}$ 分子在银表面保 持 或基本保持原来的形状. 同时,由于 $\mathrm{C}_{60} 、 \mathrm{C}_{70}$ 分子高的电子亲合 ${ }^{60}$, 使得它们与银表面的电荷 转移很难发生, 化学吸附的可能性不大, 这与我们的结论是一致的. 另外, $\mathrm{C}_{60}$ 和 $\mathrm{C}_{70}$ 分子的 扫描隧道显微镜研究表明 ${ }^{40,111}$, 它们在金表面是活动的, 也就是说 $\mathrm{C}_{60} 、 \mathrm{C}_{70}$ 分子与金的相互作 用并不强,这也为我们的结论提供了旁证.

此外, 我们还测量了 $\mathrm{C}_{70}$ 分子 SERS 信号的积分强度与溶液浓度之间的关系. 为此, 我 们配了 $1.3 \times 10^{-1} \mathrm{~mol} / \mathrm{L}$ 的 $\mathrm{C}_{70}$ 甲苯溶液, 依次稀释一倍, 得到 $6.5 \times 10^{-9}, 3.2 \times 10^{-9}, 1.6 \times$ $10^{-9}, 8.0 \times 10^{-6}, 4.0 \times 10^{-6} \mathrm{~mol} / \mathrm{L}$ 不同浓度的溶液。按本文实验部分描述的方法, 得到了不

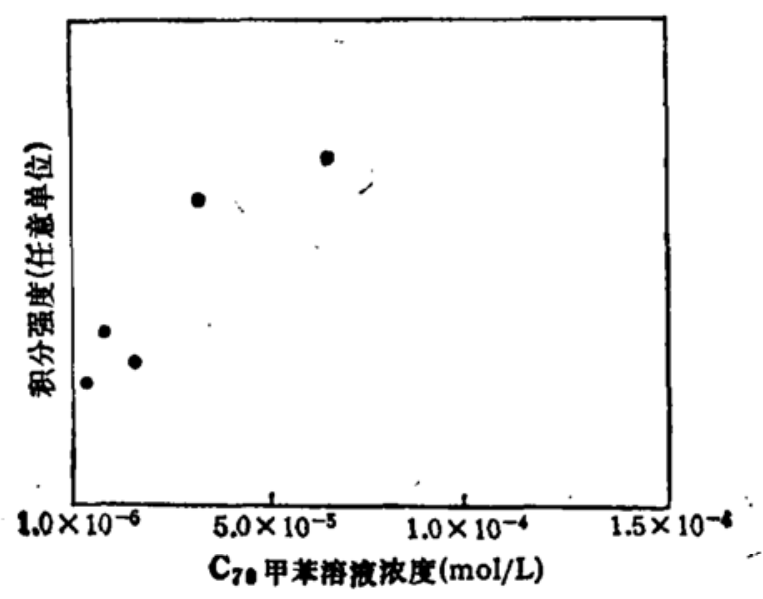

图 3 C ${ }_{n}$ 分子 SERS 积分强度与浓度的关系 
同浓度下 $\mathrm{C}_{10}$ 分子的 SERS 谱, 取 1182 和 $1228 \mathrm{~cm}^{-1}$ 两蜂积分强度之和, 得到实验数据点绘 于图 3.

从图 3 看出, 随着溶液浓度的增加, SERS 强度趋于饱和, 此时对应单分子层吸附, 浓度 范围为 $(5 \pm 3) \times 10^{-5} \mathrm{~mol} / \mathrm{L}$.

致桴感谢李蔽远研究员，甘子钢教授，杨国桢、杨乾声研究员，解思深副研究员有益的讨 论.

\section{类文献}

[1] Kroto, H. W. et al., Nature, 318(1985), 162.

[2] Kratuchmer, W. et al., Chem. Phys. Lett., 170(1990), 167.

[3] Bethune, D. S. et al., Chem. Phys. Lett., 179(1991), 181.

[4] Wu, Z. C. et al., Chem. Phys. Lett., 137(1987), 291.

[5] Stanton, R. E. et al., J. Phys., Chem., 92(1988), 2141.

[6] Weeks, D.E., J. Chem. Phys., 90(1989), 4744, Chem. Phys. Lett., 144(1988), 366.

[7] Mo, Y. 1. et al., Swrf. Sci., 133(1983), L452.

[8] Meilunas, R. et al., J. Appl. Phys., 70(1991), 5128.

[9] Curl, R. F. et al., Science, 242(1988), 242.

[10] Wilson, R. J. et sl., Neture, 348(1991), 621.

[11] Wragg, J. L. et al., Neture, 348(1991),623. 